\title{
Development of compact neutron sources
}

\author{
John M. Carpenter ${ }^{1, *}$ \\ ${ }^{1}$ Nuclear Technologies Division of the Neutron Science Directorate, Oak Ridge National Laboratory, Oak Ridge, TN.
}

\begin{abstract}
Many small research reactors, neutron sources built in the 1950s and 1960s are being shut down. The activities that these supported have therefore ended, which motivates their replacements with new facilities. Compact accelerator-based neutron sources under development are able to take up many of those activities. This paper paints the background for these developments, summarizes the replacement technologies, relates recent work that supports them, and alludes to some of the new activities that they enable.
\end{abstract}

\section{Small research reactors}

During the 1950s and 1960s, numerous laboratories and universities built and operated several dozens of research and test reactors (distinguished from power reactors). That was the optimistic era of "Atoms for Peace" programs around the world. The reactors were of many different types, operating at total thermal powers between 1 and $\sim 10$ MW and providing steady thermal neutron fluxes between $10^{12}$ and $10^{13} \mathrm{n} / \mathrm{cm}^{2}$-sec. The table below presents a representative list.

Most have offered materials irradiation (neutron damage) and activation analysis facilities, beams for neutron cross section measurements, and capabilities for medical and industrial isotope production. They also provided for reactor physics tests and included arrays of instruments for slow-neutron scattering research. In addition, they supported nuclear data and nuclear astrophysics measurements and still more applications such as the following: materials science neutron scattering studies of atomic structures and motions, neutron-induced radiation damage in power reactor materials, cross sections for design and production of medical isotope production systems, and cross sections for neutron-modulated nuclear reactions relevant to astrophysical isotope production. Around most of these reactors grew programs of nuclear science education, small-source technology (especially moderator development relevant to both small and large sources), reactor physics tests, neutron physics and materials science instrumentation development, neutron detector improvements, radiation applications, and training. Many of these became full-fledged university Nuclear Engineering departments, which furnish undergraduate and graduate education in broad programs in radiation physics and power reactor development. About 15 neutron summer schools established in those times, as well as new ones coming into being (see Table of Neutron Summer Schools, below), train students in the use of the local facilities and for entering research facilities at the major $\left(\sim 10^{15}-10^{17}\right.$ $\mathrm{n} / \mathrm{cm}^{2}-\mathrm{sec}$ ) neutron sources based on fission (notably, for many years starting in the 1970s and still so, ILL) and spallation reactions (notably, SNS at ORNL).

Table 1. Atom for Peace-era reactors

\begin{tabular}{|l|l|l|l|}
\hline $\begin{array}{l}\text { FACILITY } \\
\text { NAME }\end{array}$ & LOCATION & KW & $\begin{array}{l}\text { OPERATION } \\
\text { DATES }\end{array}$ \\
\hline $\begin{array}{l}\text { Ford Nuclear } \\
\text { Reactor [5] }\end{array}$ & $\begin{array}{l}\text { Ann Arbor, } \\
\text { MI }\end{array}$ & 2000 & $1957-2003$ \\
\hline $\begin{array}{l}\text { Breazeale } \\
\text { Nuclear } \\
\text { Reactor, } \\
\text { PSBR }\end{array}$ & $\begin{array}{l}\text { University } \\
\text { Park, PA }\end{array}$ & 1000 & $1955-\ldots$ \\
\hline $\begin{array}{l}\text { Berliner } \\
\text { Experimentier } \\
\text { Reaktor II, } \\
\text { BER II }\end{array}$ & $\begin{array}{l}\text { Helmholz- } \\
\text { Zentrum, }\end{array}$ & 10000 & $1990-2019$ \\
\hline CP-5 & Argonne, IL & 5000 & $1954-1979$ \\
\hline $\begin{array}{l}\text { Kyoto } \\
\text { University } \\
\text { Research } \\
\text { Reactor, } \\
\pi \text { KURR }\end{array}$ & Kyoto, Japan & 5000 & $1964-\ldots$ \\
\hline PULSTAR & Raleigh, NC & 1000 & $1964-\ldots$ \\
\hline $\begin{array}{l}\text { ORPHEE } \\
\text { Gif-sur- }\end{array}$ & 14000 & $1980-2019$ \\
\hline $\begin{array}{l}\text { Yvette, } \\
\text { Iniversity } \\
\text { Reactor, MNR }\end{array}$ & $\begin{array}{l}\text { Hamilton, } \\
\text { Ont., } \\
\text { Canada }\end{array}$ & 3000 & $1959-\ldots$ \\
\hline
\end{tabular}

\section{Neutron summer schools}

The first of the neutron scattering schools seems to have been the one at the Atomic Energy Research Establishment (AERE) at Harwell, UK, established in the 1960s and related to the early research reactors and the Harwell electron-linac-based bremsstrahlung photoneutron source there. The school supported and was

* Corresponding author: carpenterjohnm@yahoo.com 
peopled largely by a community of users mostly in UK universities and the AERE research staff. That school and the UK Neutron Beam Research Unit of the UK Ministry of Science provided a model system that served the large user community, which is the same as is widely in use today.

Table 1. A list of a few past neutron schools

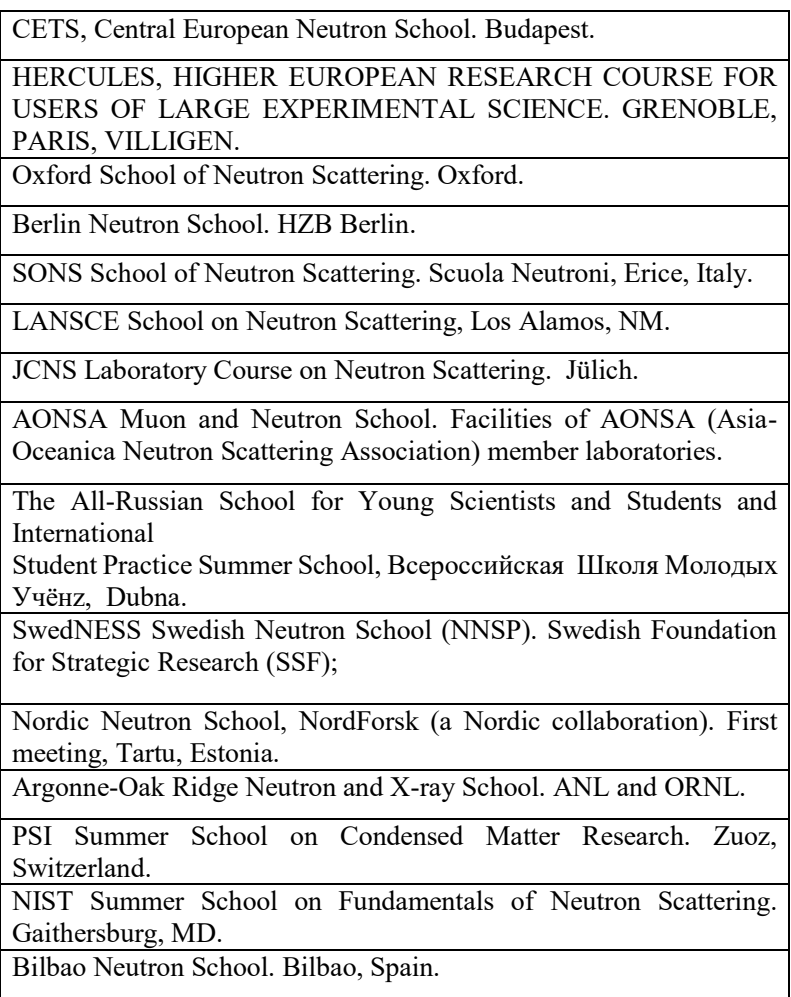

\section{What's being lost}

A large fraction of the original complement of small neutron sources has now been or will soon be shut down. Some have been dismantled on the basis of fear of reactorrelated incidents, none of which ever involved any laboratory- or university-based reactors. And some midscale reactors have been shut down to be replaced. Capabilities are being lost as the small reactors are shutting down, especially for device prototyping, techniques development, and education and practice in the field, as well as opportunities for hands-on student projects and laboratory experiments.

Also being lost as some of the larger facilities are closing are medical isotope production facilities (especially for $\mathrm{Mo}^{99}$ production), a significant fraction of materialsscience neutron-scattering capabilities, and facilities for neutron-induced transmutation doping of high-purity silicon to produce precisely controlled volumetric n-type $\mathrm{P}^{31}$-doped material for use, for example, in photovoltaic cells (the reaction is $\mathrm{Si}^{30}+\mathrm{n} \longrightarrow \mathrm{Si}^{31} \rightarrow \mathrm{P}^{31}+\mathrm{e}^{+}$). Also diminished are the concentrations of expertise of engineers and scientists residing there and the consequent loss of bases for education and training of young scientists.

\section{New sources}

All these losses motivate development of new neutron facilities, probably compact, small, accelerator-driven neutron sources, CANS, and based on low-energy (typically less than $100 \mathrm{MeV}$ particle energies) neutronproducing charged-particle reactions. Simply put, it's not that CANS are much better than reactors, it is that they are different, with a broad range of applications that are now being elaborated. Most CANS operate on d,d reactions ( $2 \mathrm{MeV}$ neutrons), d,t reactions ( $\sim 14 \mathrm{MeV}$ neutrons $), \mathrm{p}, \mathrm{Be}$ reactions $(\sim 2 \mathrm{MeV}$ neutrons), or p,Li reactions ( $\sim 2.4$ $\mathrm{MeV}$ neutrons). Operation can be either steady or pulsed. Slowing down in room-temperature moderators, these produce Maxwellian neutron spectra with temperatures $300 \mathrm{~K}$, mean energies $0.025 \mathrm{eV}$. As sources of neutron beams, accelerator-driven sources compensate for losing some of the reactor-based installations. Furthermore, the accelerator-based facilities are more than neutron sources; they are also sources of charged-particle beams useful for other purposes.

By comparison, reactors are steady sources, operating continuously, wherein fission neutrons have average energies of about $2 \mathrm{MeV}$ and moderated neutron spectra have average energy $0.025 \mathrm{eV}$ (corresponding to the moderator temperature $\sim 300 \mathrm{~K}$ ). Both CANS and reactor types adapt to cold moderators, producing neutron spectra with temperatures as low as $20 \mathrm{~K}$, depending on the moderator temperature. For further information consult Carpenter and Loong 2015 [1].

\section{Compact Accelerator-driven Neutron sources}

\subsection{UCANS - Union for Compact Accelerator- driven Neutron sources}

UCANS is a loosely organized collaboration of international laboratory and university personnel that meets about once a year or year-and-a-half. Laboratories volunteer their sponsorship, and leadership passes to a representative from the sponsor of the next meeting. Scientists from about 22 laboratories now participate in UCANS, some from institutions with currently operating CANS, such as LENS at Indiana University, Bloomington, and CPHS at Tsinghua University, Beijing. Many come from where CANS are under development, such as LENOS at the Legnaro Laboratory, Italy; the ESSBILBAO source in Bilbao, Spain; SONATE in France; and Era-Nova and HBS in Germany. Details will be found in the proceedings of this (Paris) meeting, UCANS VIII, where about 100 scientists took part. About 50 scientists took part in the 2018 meeting, UCANS VII, in Bariloche, Argentina. Several active, small ex-UCANS groups, for example in Japan and Korea, meet frequently in local 
venues. The next UCANS meeting (UCANS IX) will be held in Japan, in late 2020. Consult the website ucans.org.

The topics covered in the 2018 UCANS VII meeting were Accelerator and beam optics, Neutron detection, Nuclear astrophysics and nuclear data, Target radiation damage and heat removal, CANS projects and innovative instrumentation, Medical applications, Material characterization, Computer simulations and data analysis software, Optical devices, Other applications of CANS, and Education. See Carpenter, et al. 2018 [2]. The 2019 meeting in Paris, UCANS VIII, is the first UCANS meeting recorded in a published proceedings. Consult www.ucans.org for current information.

\subsection{A conceptual CANS installation}

The figure is a schematic representation of a compact accelerator-based neutron source. Such systems are either purchased from existing suppliers (smaller systems) or designed and built in-house (larger ones) to local specifications.

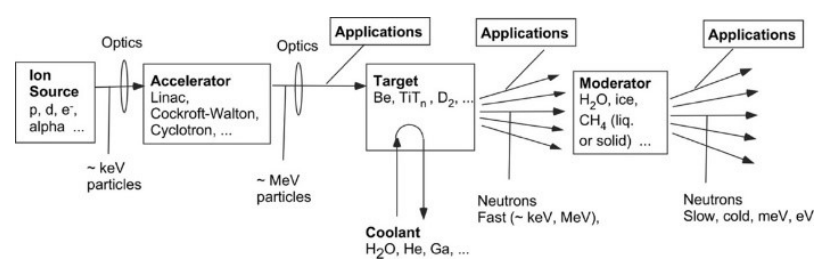

Fig. 1. Caption of the Figure 1. Below the figure.

\subsection{Applications}

Existing CANS support a wide variety of applications (Anderson, et al. 2017 [3]), for example, in the developing field of characterizing cultural artifacts (Kardjilov and Festa 2017 [4]). Several groups are developing and deploying portable neutron radiography technology for nondestructive infrastructure (roads and bridges) inspection and contraband nuclear materials (cargo) detection. Fissile materials give themselves away by emitting fission-generated neutrons that return with a time and energy signature detectably distinct from those scattered from common nonfissionable materials. CANS cargo inspection facilities are probably inexpensive enough to deploy permanently at ports where they are needed and to justify mobile inspection CANS stationed to move around when called for.

CANS are well-suited for simulations of single-event upsets (SEUs) caused by fast-neutron scattering in semiconductor devices in the high atmosphere. For these purposes, it would be easier in CANS to tailor neutron spectra than in the large facilities. Also, some of materials-science investigations that researchers carry out with higher resolution and at higher rates of throughput at the major sources rely on preliminary tests at a small source. Furthermore, a long-foreseen and hoped-for application of CANS in boron capture neutron therapy, BNCT, awaits development of boron-containing cancertumor-seeking pharmaceuticals. And there is pressing need for alternatives to reactor-produced medical isotopes, notably $\mathrm{Mo}^{99}$, but other isotopes also, where hopes lie with accelerator-based production. Table 4.3 of Anderson, et al. 2016 summarizes characteristics of CANS useful for many categories of applications and includes detailed descriptions of those applications and facilities.

\subsection{An example}

The 2-MW Ford Nuclear Reactor (criticality 1957) at the University of Michigan's Phoenix Memorial Laboratory is an example of a response to the shutting down of an Atoms for Peace reactor. There, the Nuclear Engineering and Radiological Sciences Department has installed a d,d (2.2 MeV neutrons) and a d,t (14 MeV neutrons) neutron generator in its new Neutron Sciences Laboratory and an array of several low-energy charged-particle accelerators $(\mathrm{p}, \mathrm{d}, \alpha, \ldots)$ in its Ion Beam Laboratory. These serve both teaching and research purposes involving students and faculty (see [5] for more details).

Throughout, these applications follow from the intrinsic advantages of CANS over reactors and the large, multiuser neutron facilities: low acquisition and maintenance costs, flexible scheduling, lighter safety concerns, easier access, local management, and more.

\section{Acknowledgement}

The work of Oak Ridge National Laboratory is supported by the U.S. Department of Energy, Office of Science, Office of Basic Energy Sciences, under contract 4000149663, and of Argonne National Laboratory under Contract DE-AC02-06CH11357.

\section{About the author}

John M. Carpenter is a Senior Physicist, retired, Emeritus Scientist, and Distinguished Fellow of Argonne National Laboratory, now attached to the APS Engineering Services Division. Until 1975, he served for ten years as Professor of Nuclear Engineering at the University of Michigan. He is the spokesperson for UCANS.

Carpenter serves as a consultant to the Nuclear Technologies Division of the Neutron Science Directorate of Oak Ridge National Laboratory, Oak Ridge, Tennessee. 


\section{References}

[1] J. M. Carpenter, and C.-K. Loong, 2017. Elements of Slow-Neutron Scattering, Cambridge University Press.

[2] J. M. Carpenter, D. Baxter, and R. Granada (2018). UCANS VII Meeting Summary, Neutron News, 29, Number 2.

[3] I.S. Anderson, C. Andreani, J. M. Carpenter, G. Festa, G. Gorini, C.- K. Loong, and R. Senesi (2016).

Research opportunities with compact accelerator-based neutron sources, Physics Reports doi:10.1016/j/physrep.2016.07.007.

[4] N. Kardjilov and G. Festa, (2017). Neutron methods for archeology and cultural heritage, Springer International Publishing Switzerland, 10.1007/978-3-31933163-8.

[5] J. J. Duderstadt (2018). The University of Michigan Nuclear Engineering and Radiological Sciences: A History, The Millennium Project, Ann Arbor.

See also an earlier version of this paper, (2019) J. M. Carpenter, "Development of Compact Neutron Sources."Nature Reviews Physics 1, published online 28 January 2019, pp.177-179. Issue date March 2019. 